\title{
SOME MULTI-DIMENSIONAL HARDY \\ TYPE INTEGRAL INEQUALITIES
}

\author{
L.-E. Persson AND E. P. UshaKova
}

Abstract. In this paper we prove some new results concerning multi-dimensional Hardy type integral inequalities and also some corresponding limit Pólya-Knopp type inequalities.

Mathematics subject classification (2000): 26D10, 26D15, 26 D07.

Key words and phrases: Integral inequalities, weights, multi-dimensional Hardy operator, multidimensional geometric mean operator.

\section{REFERENCES}

[1] S. BARZA, Weighted multidimensional integral inequalities and applications, PhD Thesis, Department of Mathematics, Luleå University of Technology, 1999.

[2] A. Gogatishvili, A. Kufner, L.-E. Persson AND A. Wedestig, An equivalence theorem for integral conditions related to Hardy's inequality, Real Anal. Exchange 29 (2) (2003/04), 867-880.

[3] A. Kufner, L. Maligranda AND L.-E. Persson, The Hardy inequality - about its history and some related results, book manusript, 2006 (160 pages).

[4] A. Kufner And L.-E. Persson, Weighted inequalities of Hardy type. World Scientific, New Jersey/London/Singapore/Hong Kong, 2003 (357 pages).

[5] L.-E. PERSSON AND V. D. STEPANOV, Weighted integral inequalities with the geometric mean operator, J. Inequal. Appl. 7 (2002), 727-746.

[6] L.-E. Persson, V. Stepanov AND P. WAlL, Some scales of equivalent weight characterizations of Hardy's inequality: the case $q<p$, Math. Inequal. Appl., to appear.

[7] E. SAWYER, Weighted inequalities for two-dimensional Hardy operator, Studia Math. 82 (1) (1985), $1-16$.

[8] A. Wedestig, Weighted inequalities of Hardy-type and their limiting inequalities, PhD Thesis, Department of Mathematics, Luleå University of Technology, 2003.

[9] A. WEDESTIG, Weighted inequalities for the Sawyer two-dimensional Hardy operator and its limiting geometric mean operator, J. Inequal. Appl. 4 (2005), 387-394. 